\title{
Online Games Virtual Products-Transaction and Value
}

\author{
Meng Wang \\ School of Economics, Southwest Minzu University, Chengdu 610041, China. \\ 1090474669@qq.com
}

\begin{abstract}
With the popularity of the Internet, online games have gradually become one of the most popular entertainment means. Online games give birth to the online games virtual products. Meanwhile, the products keep enriching their meaning in the continuous development of online games and virtual products transaction. The value of online games virtual products tends to become clearer in the process of its development. Online games virtual products, from simply improving players' game experience in the virtual world, have gradually developed into a commodity with abundant practical value. Online games virtual commodity trading market has changed from the small-scale trading between players, to the B2C transaction between game operators and players, and now with the participation of many professional third-party platforms. Online games virtual products transaction has become much more standardized and professional. The practical value of online games virtual products has also been reflected in the development of transaction.
\end{abstract}

Keywords: Virtual products, online games, virtual transaction, value analysis.

\section{Introduction}

With the rapid development of the Internet, online games have gradually aroused public interests as a brand new type of entertainment that is different from traditional ways. Online games have already become a significant industry. Meanwhile, with the application of the new technology and the innovation of the game methods, the operating income of online games industry has also increased in a large stride.

According to the Report on China Game Industry Development in 2017 jointly released by the China Culture and Entertainment Association Information Center and Entrains on November 28th 2017, the overall operating income in 2017 was approximately 218.96 billion Yuan, with year-onyear growth of $23.1 \%$, among which online games extremely contributed to the industry operating growth. The operating income of the first three quarters reached 151.32 billion Yuan, and the annual operating income is expected to be about 201.1 billion Yuan, with year-on-year growth of 23.1\%.[1] The revenue of online games mainly comes from the players' purchase of available game time, virtual items and the income of peripheral products. The income of virtual items is the crucial source of income for the online games corporate; namely online games virtual products absorb a lot of funds. At the same time, the secondary market of online games virtual products keeps developing. Online game virtual product trading is very prosperous, ranging from between players and players, to between players and platforms. Many players and even merchants make profits through the trading of online games virtual products. The participations of intermediate platforms such as C5GAME and IG e-sports trading platform make the online games virtual transaction more professional and safe.

Virtual product, as a kind of intangible product that originates from online games, expands public awareness of products. In the early age of online games, online games were just a simple way of entertainment. Their commercial value has not been developed; when the second generation of online games was generated, the commercial value came into being, and it was paid by time; not until the emergence of the third generation of online games did the online games virtual products board the stage of history. The value of online games virtual products has been widely discussed in the academic circles, but has not been well defined. Nowadays, online games virtual products have become more and more mature, and the outline of online games virtual products has become much clearer as well. 


\section{The Generation, Development and Market Status of Online Games Virtual Products}

\subsection{Overviews of Online Games}

For the definition of online games, Wang Wei and Xu Xiao are convinced that online games refer to the computer games that rely on the Internet for interactive entertainment by multiple players [2].

Li Nonie and Li Yi argue that first online game in a real sense began in 1969. Based on the Space War that was produced by MIT students, Rick Brooke used PLATO (Programmed Logic for Automatic Teaching Operations) system wrote the software that allows two users to simultaneously use remote connection to play games. Goo Bing thinks that online games at this stage have the following characteristics: firstly, the games lack continuity [3]. Once the computer restarts, the related information will be lost. Hence, the game cannot imitate a world with non-overlapping time period [4]; secondly, limited by the non-unified computer hardware and software, the games cannot run across system in that they are basically set up on the mainframes of colleges. They can just run inside a certain terminal.

The second generation of online games started in 1978, when the two students from University of Essex, Roy Trumbshaw and Richard used the PDP-10 computer from Data Equipment Corporation (DEC) and wrote the first multiple player online game, called Multi-User Dungeon online game, namely MUD game. Online games, for the first time, had the independent service providers and service platforms. Players could use any computer with a modern to connect to the Internet, and the game data can be conserved in the games. Nevertheless, the network transmission capacity was relatively low. At this time, online games were mainly text interaction. At this stage, online games started a time-based charging profit model.

The third generation of online games began in 1996. The concept of massively multiplayer online role-playing online games (MMORPGs) was born with Archetype's "Mercury 59" being the symbol. In 1997, Ultimo Online: Shattered Legacy, a massively multiple player online role-playing game, was officially charged by monthly fees.

Online game in China began with a MUD game called Ode to Gallantry in 1992. It really started from Lain Zheng Game World in June 1998. Liang Lei thinks that the emergence of online games as a MMORPG was in 1999 when Hua Cain Software launched Lager Company's King of Kings in mainland China [5]. The development of China online games mainly followed the footsteps of foreign countries. The online games that could create hot spots among domestic consumers such as World of Warcraft or DOTA2 are mainly foreign online games titled by Chinese enterprises.

\subsection{Generation, Definition, and Classification of Online Games Virtual Products}

\subsubsection{Generation Background of Online Games Virtual Products}

Instead of the non-commercial entertainment way at the beginning, online games have gradually been commercialized. From the beginning of the sales of game time, to the emergence of online games virtual products trading with virtual currency centralized media, and to today's emergence of online games virtual products directly based on exchange media, virtual products have become one of the important parts of the ability to generate wealth in online game industry.

The original birth of virtual products came from the 1999 massively multiplayer online roleplaying online game (MMORPG). However, with the developing of virtual products, many kinds of virtual products do not need to rely on online games. Therefore online games virtual products cannot be equal to virtual products.

\subsubsection{Virtual Products and Online Games Virtual Products}

$\mathrm{Wu}$ Hong and Peng Hue hold the view that there are about two definitions about virtual products: Virtual product refers to the network content that can be transmitted and distributed via the Internet, such as online games, digital products and digital service, of which the essence is computer program or code. It refers to the so-called commodity that does not have an objective entity, but is able to 
satisfy consumer demands. Such commodity is merely a symbol or concept. The first definition is the most widely used one. [6]

The characteristics of virtual products are summarized as follows: Firstly, intangibility is the most essential feature that tells virtual products apart from others. Virtual products have to rely on computer and the Internet. That is to say, it does not have any physical representation or rely on any entity, so its value can only be achieved by the Internet. Secondly, digitalization is another feature of virtual products. Digitalization means the conversion via number of complex information into digital model information that can be computed and measured by computers, the most basic units being 0 and 1 .

Virtual products contain online games virtual products. Firstly, online games virtual products only exist in online games. In other words, online games virtual products are based on online games, and online games are carriers; secondly, the existence of online games virtual products has a time limit, generally due to the existence of the online game.

The broad definition of commodities in mainstream economics and accounting is that the product can be used in the trade, satisfy consumer needs, and provide utility. In combination with the characteristics of online game virtual products, the definition can be concluded: based on computers and the Internet technology, online games virtual products are the products that can be used for trade, satisfy consumer needs, and provide utility, with the carrier of online games.

\subsubsection{Classification of Online Games Virtual Products}

The online games virtual products are divided into two types according to their circulation liquidity: limited circulating online games virtual products and free-flowing circulating online games virtual products.

Limited circulating online games virtual products cannot be freely circulated in the market. Take the 5v5 MOBA (Multiplayer Online Battle Arena) League of Legends for instance. The virtual products are mainly the character skin, the ID avatar, or other decorative virtual products. Players purchase the virtual products in the game by buying game point cards or transferring money to recharge the game currency in the League of Legends, or they directly purchase the virtual products from the shopping website operated by the game company. Nevertheless, the virtual products in each game account cannot be circulated through accounts. That is to say, the products in an account cannot be transferred to another account by any means.

Free-flowing circulating online games virtual products can be freely circulated in the market. Take DOTA2 as an example. Similar to League of Legends, it is mainly based on decorative products of the characters in the game; however, the difference is that virtual products in DOTA2 can be freely transferred through any player's account. Players are able to purchase the decorations in other players' accounts.

\subsection{Trading of Online Game Virtual Products}

\subsubsection{The Status Quo of Online Game Virtual Products Trading}

In the early stage of online games development, virtual resources can only be obtained in the game. The virtual products are randomly distributed by the Server to the players or when players reach a certain default requirement of the game system. Besides, the players may trade with other players, barter or buy in game currency. In some games, many players also by the gear or game cash created by other player's labor. This way of acquiring virtual products is still reserved in many games, but not for the virtual products with high price and profits. The demand for virtual resources in online games leads to the formation of online games virtual products market.

$\mathrm{Xu}$ Weanling divides the online games virtual commodity market into primary and secondary market [7]. The first part is in-game trading market (primary market). In primary market, game operators offer all kinds of online games virtual products in the game or official trading website. Players can get some virtual products by reaching some default requirements of the game system, such as the game level, the number of enemies killing, daily tasks, etc. More importantly, players purchase virtual products by recharging the game currency or directly transferring the money. The transaction of primary market mainly occurs between the player and the operator (Figure 1), and the 
payment is made by the game currency or actual currency. The transaction ways are mostly one-way vertical transactions between operators and players. The second part is trading market outside the game (secondary market). Secondary market transaction is the horizontal trading between players and players. These transactions are all reversible. Due to the limited circulating online games virtual products, there are still many transactions in secondary market that are marked by game accounts. Because limited circulating online games virtual products cannot be freely traded and transferred, many players that have some specific demand for virtual products may buy the game accounts to obtain the virtual products. The author regarded such account-based purchase as a "package transaction".

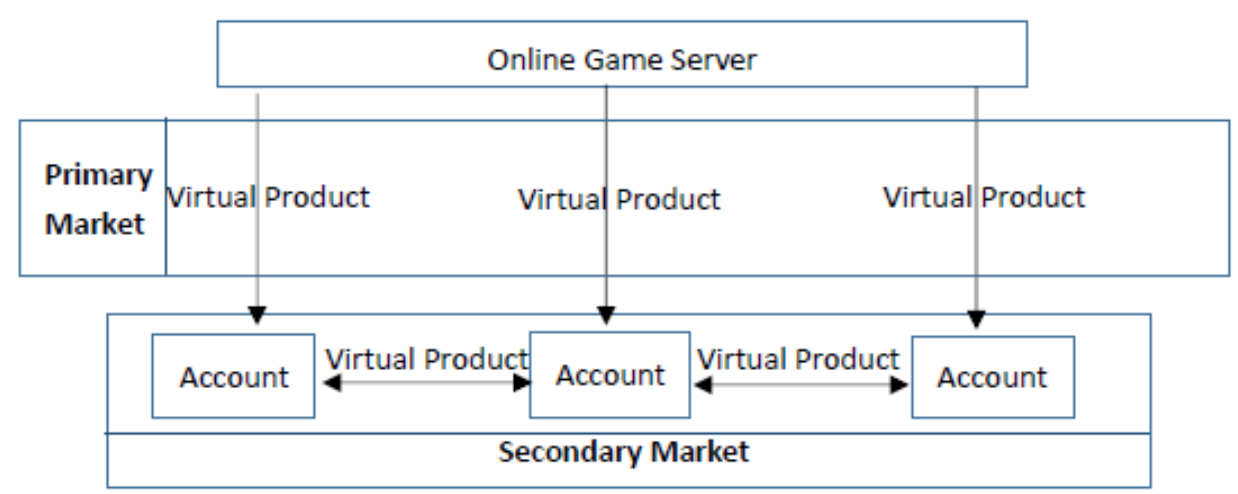

Fig 1. Online Game Virtual Products Market

When it comes to the package transaction, it is not only limited to the transaction of online game virtual products that mainly consist of limited circulating online games virtual products. For some free-flowing circulating online games virtual products covered games, if these players no longer play these games, they might also use the package transaction to stop loss in the case of lots of investment (time, money). In addition, for some accounts with certain value, such as a high level, or with numerous achievements, packaged transactions also exist as well. The circumstance, by nature, is not the transaction of online games items or decorations, but a transaction that is purely around the value of game account itself.

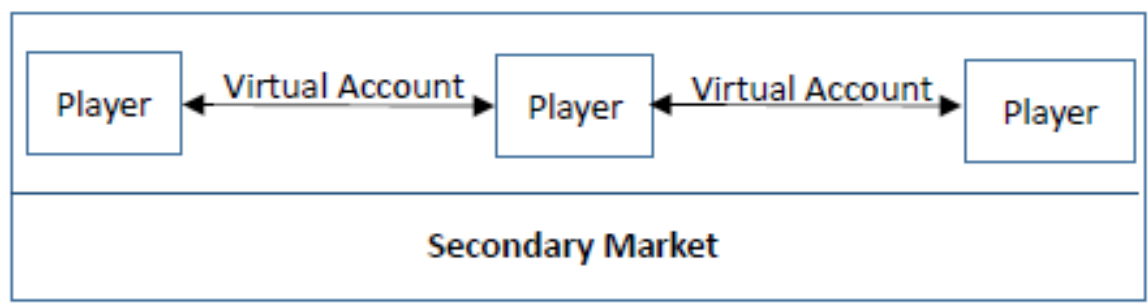

Fig 2. Packaged Transactions

\subsubsection{The Transaction Mechanism of Online Games Virtual Products}

In primary market, the operator directly provides the quotes of online games virtual products directly in the game or on the official B2C trading platform, in the game currency or the real money. The buyers can directly purchase and finish the transaction after payment. For instance, the products provided by CS: GO's primary market are mainly boxes and keys. The decorations that players unpack after purchasing the items are secondary virtual products. The probability of obtaining secondary virtual products is totally different.

Secondary market is also divided into several trading modes: (1) professional platform trading, such as C5game, IGXE and other third-party trading platform, provides buyers and sellers with dynamic quotations based on their bids, and their quotations are displayed separately in the platform. The type of mechanism is similar to the continuous transaction in the securities trading mechanism, but it is slightly different. Since the transaction of such third-party platform is attached to the game 
platform itself, after the platform completes the transaction, the virtual products will be stored in the buyer's trading platform accounts. The trading platform robots may send a transaction request with a price of 0 to the game platform account (the payment has already been completed in the trading platform), until the buyer confirms the result. What is worth mentioning is that such platforms offer bargaining opportunities to buyers and sellers; (2) non-professional platform trading. Represented by Taobao, private merchants operate by themselves. The differences of it from professional platforms are that they do not offer buyer's quotations. After the buyers place an order, the virtual products are directly delivered into the game platform; (3) black market transaction, buyers and sellers alike negotiate the price. After both two parties reach an agreement, they enter the game and finish the delivery according to the different platforms. This kind of transaction is completely realized by the buyers and sellers' communication and conversation. Since the buyers and sellers do not know each other, the time of payment and delivery is not fixed, and the security cannot be guaranteed.

\section{Value Analysis of Online Games Virtual Products}

\subsection{The Value and Value Source of Online Games}

The value of online games virtual products is mainly based on two understandings. Chen Weanling thinks that, because many players devote long-term time, energy, labor, money and even emotional input to the game gold coins, gears and other virtual resources, the investment of game developers and operators in creating the virtual games may be comparatively negligible. The value of online games virtual products should be defined as the indiscriminate labor of game players [8]. Feng Honiara argues that the value of virtual games is the mental and physical labor of game developers and operators, because the game resources are pre-made by software engineers. After an online game is produced, the process of players spending time and money to get virtual products is just a process of consuming games. The value of online games virtual products ought to be the indiscriminate human labors of game makers [9].

Judging from the current wide variety of online games virtual products, these two understandings are obviously flawed, and they cannot truly describe the value of online games virtual products. The two understandings mentioned above are obviously a little bit one-sided. Either the value of online games virtual products is entirely created by the players, or the value is entirely created by the game makers.

The first understanding naturally excludes the game publishers and operators' labor investment of online games virtual products. Additionally, the virtual products of games like League of Legends are made by game publishers and distributed or sold by game operators. The production of a character skin requires numerous labors, from design to modeling. The second understanding, on the other hand, ignores the players' labor. The most direct presentation is that it is hard to explain that some small studios in China hire some employees to play games and get the gold coins and gears, and then sell them to the players in need, because it is difficult to deny that the these "game workers" are not making an effort.

Therefore, the value of online games virtual products needs to be differentiated according to the way in which they are created. In other words, it is essential to clarify the period during which the game publisher and players pay for labor. Personally, the labor paying periods are divided into several stages: (1) original production period, the period when game publishers and operators make and distribute games. It ends when the game heads for the market. The value of some parts of online games virtual products is completely formed in this period. (2) Expansion period, players need to pay time to obtain the virtual products that have already been preset by the game publishers and operators. The value of online games virtual products during this period is the combination of the labor of players and game firms. 


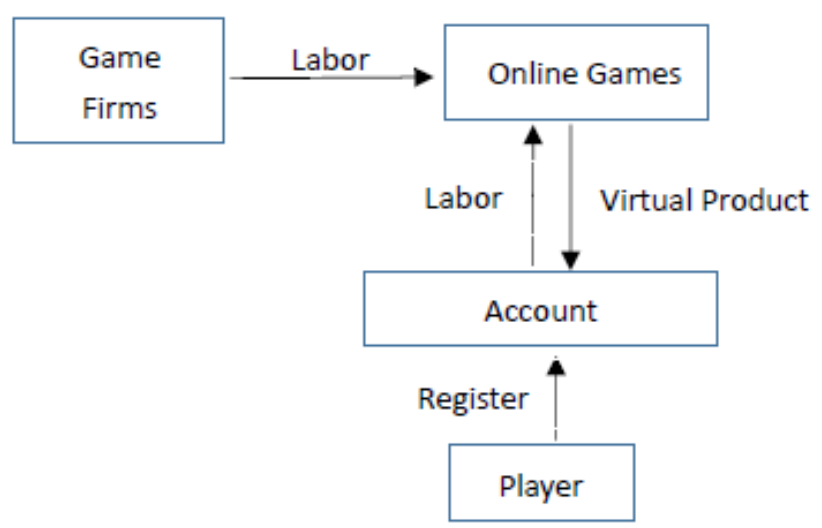

Fig 3. Value Sources of Online Games Virtual Products

\subsection{The Use Value and Exchange Value of Virtual Products}

In terms of the use value of products, it means the attribute that may satisfy a person's certain needs, namely the utility of the items. Online games virtual products only exist in the online games, and the use value of them is limited to the inside of online games, not related to the real world. Hence, the use value of online games virtual products is reflected on the utility that the players can obtain from the virtual products.

Specifically, the mounts in the World of Warcraft enable the players to move faster in the game world, that is, to offer help for the players to play games, and the use value is functional. In a colloquial metaphor, the use value of the mounts in the game is what the use value of vehicle in the real world, except that the realization environment of the value is different. For the competitive games like CS: GO and DOTA2, the virtual goods are called "decorations" by the players. Players can decorate and embellish the characters or environment in the game, but it does not have an influence on the game of the player's, which means that the player will not get faster speed or more accurate shooting ability. The use value of it is for aesthetics.

When it comes to the exchange value of online games virtual products, scarcity is the most dominant factor that influences the exchange value. Take CS: GO for instance. At the beginning of 2008, the final League Major of CS: GO ended up in Boston, USA. The Cloud9 defeated Faze, grasped the final trophy and won a prize of 500,000 US dollars. The sniper Skadoodle in the Cloud9 has attracted a large amount of CS: GO fans' attention with his outstanding performance. The game publisher launched a brand new souvenir of 2017 Krakow Special champions with the champion team Skadoodle's signature " the Legend of the Dragon", which was soon sold out at a whopping price of 61,052.63 US dollars. It is hard to imagine that a decorative virtual product can be sold at the price of a mid-range family car. There are two reasons that may cause the whopping price transaction. Every CS: GO contest will dispute a small probability of race map weapon commemorative boxes to the players who are watching the live contest. There are certain kinds of accessories in the commemorative boxes that can be opened infinitely. However, the players have to purchase the key to open the box, and the probability of opening the box to obtain each virtual product is different. The number of the audiences in a game contest is usually around 400,000 to 500,000; however, during this period only thousands of commemorative boxes are distributed. The probability of getting the decorations like the Legend of the Dragon is extremely small. In conclusion, obtaining the decorations with high rarity is similar to finding a needle in a haystack. The effects of scarcity on online games virtual products are also more than evident.

\subsection{The Consumption Value of Online Games Virtual Products}

Function value. Online game virtual product relies on online games, and is the derivative of online games. The function value of online games is to enable players to possess a better game experience, thus meeting their entertainment demands in the online game entertainment mode. The specific representations are as follows: mounts in World of Warcraft on the speed improvement of the character movement in the game; cards in Hearth Stone on the enlargement of player's game routine 
and the enhancement of the player's deck strength; weapons in Assault Fire to increase the hit rate and reduce the effects of recoil force, etc.

Social Value. Online games provides players with a "beautiful new world" to temporarily escape from the real life. Players do not know each other. The only feature that can indicate player's identity is the game character. In reality, few people can become the billionaires who drive luxury cars, but in online games the achievement of these conditions only requires players to invest thousands of money. Virtual products are irreplaceable in the fields of identity displaying and character role shaping in the game world.

Emotional value, as has been mentioned above, online games provide players with a "beautiful new world". In the game world, players could escape from many troubles and unhappiness in the real life. Virtual products offer players the identity and status beyond their limitations of their own lives (in game). That is also the reason why many online games fans are willing to pay for online games virtual products at a price that we ordinary people find it hard to understand. In addition, with the prosperous development of electronic competitive sports, many excellent professional players and teams have emerged. Like Olympic Games and other major sports events, the fascinating athletes are one of the reasons why many people fall in love with a kind of sport, and such groups of people are especially keen on buying peripheral products with athletes' signatures or endorsement. Online games are no exception. The virtual products related to famous professional gamers are also extremely popular among players.

Cognitive value. Online games virtual products keep launching a variety of virtual products, partly because they want to satisfy players' curiosity and desire for the new things. Similarly, it is also a common way for game makers to attract new consumers, namely launching the new virtual products to recognize and explore the potential users' need of cognitive value.

Conditional value. Since online games virtual products rely on online games, many virtual products, such as those that are sold in the limited time for specific activities, or virtual products with special commemorative meaning, can bring enormous psychological satisfaction and utility to the players due to their scarcity. Thus, they will create great conditional value for players.

\section{Analysis of the Practical Meaning of Online Games Virtual Products}

\subsection{Investment Value and Risk of Online Games Virtual Products}

The use value of online games virtual products lies in the fact it can satisfy players' needs of improving game experiences, which is also the reason why so many players are willing to pay for the virtual products. In addition to the game currency, many online games virtual products share the characteristics of "scarcity". When the virtual products can be freely circulated among the players, the price of these online games virtual products may change with their scarcity. In other words, such price change is fundamentally due to the change in supply and demand. Therefore, when the market price is higher than the purchase price, there is an opportunity for arbitrage.

There are two main investment ways of online games virtual products, directly investing in original products in the primary market, or investing in secondary products in the secondary market. The risk of the former is much higher, of which the risk comes from the uncertainty of the probability of second products, as well as the huge price gap between virtual products with different scarcity levels. The risk of the latter lies in the liquidity after the purchase is finished. The high-priced virtual products generally have poor liquidity, while the low-priced products are not highly worth investing, due to their sufficient supply. Hence, there is a lack of value-added space.

Online games virtual products are also faced with certain external risks. For the secondary trading platform, the conflict between the trading platforms and gaming platforms may lead to the loss of liquidity. Not so long ago, Valve froze the trading of Steam decoration trading platform C5game users. Even though in the subsequent communication, Valve confirmed that there is no problem in the decoration trading business of C5game, it clearly suggested that the frozen C5game users' items could not get a ban reserved. C5game trading platform said that it would pay $80 \%$ of the platform profit to compensate for the users' loss. Under the theoretical circumstances, it is expected to 
compensate $5 \%, 10 \%, 15 \%, 20 \%, 25 \%, 25 \%$ of the amount of frozen decorations each month, and complete the full-price compensation in half a year. Generally speaking, users will get some certain loss compensation. Nevertheless, the incident still brought an enormous loss to the players who inverted in virtual products. The unclear property rights of virtual products also add to the difficulty for the users to defend their rights after being defrauded or hacked.

\subsection{The Financial Value of Online Games Virtual Products}

On May 10th, 2018 Blizzard Entertainment announced that in its game over watch, it launched a $\$ 15$ charity-themed virtual product--special skin "Pink Angels" in partnership with Breast Cancer Research Foundation (BCRF). Pink Angels also aims at helping charity BCRF raise donations via the sales of virtual products in game.

Blizzard Entertainment mentioned in the agreement with BCRF that it would donate all the proceeds from the sale of "Pink Angel" to BCRF and guaranteed a minimum donation amount of $\$ 250,000$. But until the day before the virtual product stopped selling, "Pink Angel" had already raised nearly $\$ 10$ million.

Similarly, online games virtual products also play a significant role in financial aspects.

\section{Conclusion}

Even though online games virtual products have always been controversial, players still maintain a strong buying enthusiasm. The boundaries between online games virtual products and reality have also become more closely related in the creation, trading and use of online games virtual products. Online games virtual products not only provide players with spiritual pleasure. More importantly, their investment value and financial function have been discovered in the practice of the market. With the rapid development of information technology, virtual and reality will be more closely linked. Online games virtual products in the future will not fail to create more value for our world.

\section{References}

[1]. China Culture and Entertainment Association Information Centre. Report on China Game Industry Development in 2017 [R]. Entrains, 2017.

[2]. Wang Wei, Xu Xiao Bo. Research on Trading Behaviours of Online Games Virtual Products [J]. Journal of Qiqihar Junior, 5(2017), p.82-83.

[3]. Goo Bing: Analysis of Online Games Consumer Behaviours [D]. Master Thesis, Zhejiang University, China, 2006.

[4]. Li Nonie, Li Yoke. Literary Review of Online Games Industry at Home and Abroad [J]. VakeEngineering, Vol.27 (2008) No.12, p.96-101.

[5]. Liang Lei: Research on the Application and Prospect of Local Cultural Elements in Chinese Online Games Design [D]. Master Thesis, Shanxi University of Science \& Technology, China, 2008.

[6]. Wu Hong, Peng Hue. Brief Introduction to Virtual Products [J]. Journal of Tsinghua University (Philosophy and Social Sciences), 3(2010), p.51-54.

[7]. Xu Weanling: Research on China Virtual Products Trading [D]. Jinan University, China, 2007.

[8]. Chen Weanling. Analysis of Online Virtual Products--Based on Political Economics [J]. Enterpriser World, 5(2007), p.177-178.

[9]. Feng Honiara. Research on Commodity Attributes of Online Virtual Products [J]. Hebei Law Science, Vol.26 (2008) No.9, p.147-150. 